\title{
Correction to: Impact of demand forecast information sharingon the decision of a green supply chain with government subsidy
}

\author{
Wenbin Wang ${ }^{1} \cdot$ Wanying $\operatorname{Lin}^{1} \cdot{\text { Jianhu } \mathrm{Cai}^{2}}^{\mathrm{I}} \cdot$ Mengxue Chen $^{1}$
}

๑) Springer Science+Business Media, LLC, part of Springer Nature 2021

\section{Correction to: Annals of Operations Research https://doi.org/10.1007/s10479-021-04233-7}

This correction is published as typesetter overlooked several proofing corrections.

Original article has been updated.

Publisher's Note Springer Nature remains neutral with regard to jurisdictional claims in published maps and institutional affiliations.

The original article can be found online at https://doi.org/10.1007/s10479-021-04233-7.

Jianhu Cai

hzdcjh@yahoo.com

1 School of Economics and Management, China University of Mining and Technology, Xuzhou 221116, China

2 School of Management, Hangzhou Dianzi University, Hangzhou 310018, China 